\section{Increased number of intestinal villous $M$ cells in levamisole - pretreated weaned pigs experimentally infected with F4ac+ enterotoxigenic Escherichia coli strain}

\author{
H. Valpotić,' A. Kovšca Janjatović, ${ }^{2}$ \\ G. Lacković, ${ }^{3}$ F. Božić, ${ }^{4}$ V. Dobranić, ${ }^{5}$ \\ D. Svoboda, ${ }^{2}$ I. Valpotić, ${ }^{2}$ M. Popović ${ }^{2}$
}

'Department of Animal Nutrition, Veterinary Faculty, University of Zagreb, Croatia; ' Department of Biology, Veterinary Faculty, University of Zagreb, Croatia; ${ }^{3}$ Department of Zoology, Division of Biology, Faculty of Science, University of Zagreb, Croatia; ' ${ }^{4}$ Department of Pharmacology and Toxicology, Veterinary Faculty, University of Zagreb, Croatia; ${ }^{5}$ Department of Hygiene and Technology of Foodstuffs of Animal Origin, Veterinary Faculty, University of Zagreb, Croatia

\section{Abstract}

Immunoprophylaxis of porcine postweaning colibacillosis (PWC) caused by enterotoxigenic Escherichia coli (ETEC) expressing F4 fimbriae is an unsolved problem. Just as ETEC strains can exploit intestinal microfold (M) cells as the entry portal for infection, their high transcytotic ability make them an attractive target for mucosally delivered vaccines, adjuvants and therapeutics. We have developed a model of parenteral/oral immunization of 4-weeks-old pigs with either levamisole or vaccine candidate $\mathrm{F} \mathrm{ac}^{+}$non-ETEC strain to study their effects on de novo differentiation of antigen-sampling $\mathrm{M}$ cells. Identification, localization and morphometric quantification of cytokeratin 18 positive $\mathrm{M}$ cells in the ileal mucosa of 6 -weeks-old pigs revealed that they were: 1) exclusively located within villous epithelial layer, 2) significantly numerous $(\mathrm{P}<$ 0.01 ) in levamisole pretreated/challenged pigs, and 3) only slightly, but not significantly numerous in vaccinated/challenged pigs compared with non-pretreated/challenged control pigs. The fact that levamisole may affect the $\mathrm{M}$ cells frequency by increasing their numbers, makes it an interesting adjuvant to study development of an effective $M$ cell-targeted vaccine against porcine PWC.

\section{Introduction}

Immunoprophylaxis of postweaning colibacillosis (PWC) is an unsolved problem. Up today, the most promising vaccination strategies include oral immunization of pigs before weaning with live avirulent non-enterotoxigenic Escherichia coli (non-ETEC) strains carrying fimbrial adhesins homologous to those of ETEC strains present in the given swine population. ${ }^{1}$ However, the immunization against PWC with live vaccines is still difficult, for the following reasons: i) ETEC strains are only one of the essential factors of the etiology of PWC ${ }^{2}$ ii) the success of immunization depend on the presence of intestinal receptors specific for ETEC adhesins ${ }^{3}$ and on the uptake of bacterial antigens by the microfold (M) cells, specialized extensions of germinal centers of Peyer's patches $^{4}$ iii) the small intestinal mucosal immune system may develop different immune responses to the same antigens depending on the dose and form of immunogen, resulting in production of protective IgA, oral tolerance or hypersensitivity., ${ }^{5,6}$ To avoid induction of oral tolerance in developing pigs, ${ }^{7}$ the immunization strategies to control this disease include the use of adjuvants, such as levamisole. ${ }^{8,9}$ The attempts to validate the influence of levamisole on the intestinal cellular immunity against PWC, when applied alone or in the combination with live oral $\mathrm{F}_{4} \mathrm{ac}^{+}$or $\mathrm{F} 18 \mathrm{ac}^{+}$vaccines, confirmed its potentials as an immunomodulator and mucosal adjuvant. ${ }^{10,11}$ However, our knowledge about mechanisms operating at the mucosal surfaces of the small intestine following oral immunization of pigs with a live vaccine candidate $\mathrm{F}_{4 \mathrm{ac}^{+}}$non-ETEC strain is still limited. Further research should include antigen sampling microfold (M) cells providing transcytotic antigen delivery through the follicle-associated epithelium (FAE) to the underlying immune cells within the gut associated lymphoid tissues (GALT), such as ileal Peyer's patches. ${ }^{12,13}$ Indeed, it has been demonstrated that $\mathrm{M}$ cells can transport a diverse array of intraluminal microorganisms across the intestinal epithelial barrier, including $E$. coli, ${ }^{12}$ but also a variety of synthetic microparticles/nanoparticles as vehicles for mucosal vaccine delivery, $\beta 1$ integrins, pathogen recognition receptors and specific carbohydrate residues..$^{14}$ Accordingly, some intestinal pathogens exploit M cells as their entry portal to invade host and cause infections..$^{15}$ For example, the rabbit diarrheagenic $E$. coli strain is selective for adherence to intestinal M cells. ${ }^{12}$ We believe that both porcine ETEC strains and vaccine candidate non-ETEC strains utilize these cells as a target for entry/delivery to induce either an infection or protective immunity, respectively. Porcine
Correspondence: Dr. sc. Prof. Ivica Valpotić, Department of Biology, Veterinary Faculty, University of Zagreb, Heinzelova 55, 10000 Zagreb, Croatia.

Tel: +385.1.2390.144 - Fax: +385.1.2441.390

E-mail: valpotic@vef.hr

Key words: M cells, levamisole, $E$. coli vaccine, weaned pigs.

Acknowledgements: the current study was supported by the grants nos. 053-0532265-2255 and 053-0532265-2248 from the Ministry of Science, Education and Sport of Croatia. The excellent technical assistance of Mrs. Zrinka Benčina is gratefully acknowledged.

Received for publication: 12 December 2009. Accepted for publication: 5 March 2010.

This work is licensed under a Creative Commons Attribution 3.0 License (by-nc 3.0).

(C) Copyright H. Valpotić et al., 2010

Licensee PAGEPress, Italy

European Journal of Histochemistry 2010; 54:e18 doi:10.4081/ejh.2010.e18

intestinal M cells may be distinguished from the other cells residing epithelium by the expression of cytokeratin peptide $18 .^{16}$

The current study evaluated nonspecific immunogenic potentials of levamisole in promoting differentiation of porcine ileal M cells phenotype as an attractive target for mucosally delivered vaccines against porcine PWC. Therefore, we have performed identification, localization and morphometric quantification of cytokeratin 18 positive $M$ cells in the ileal mucosa of weaned pigs immunized with either levamisole or vaccine candidate $\mathrm{F}_{4} \mathrm{ac}^{+}$nonETEC strain and challenged with homologous ETEC strain.

\section{Materials and Methods}

Fifteen crossbred pigs (Swedish Landrace $\mathrm{x}$ Yorkshire) weighed $6.5 \pm 1 \mathrm{~kg}$, progeny of three litters, were purchased from a swine farm nearby Zagreb, Croatia. The pigs were weaned at 4 weeks of age, housed in the animal facility at the Veterinary Faculty University of Zagreb and fed with a standard weaner diet. Experimental and animal management procedures were conducted in accordance with the "Directive for the Protection of Vertebrate Animals used for Experimental and other Purposes" (86/609/EEC). The F4ac ${ }^{+} E$. coli strains used for either immunization or challenge infection were described in a previous study of our group. ${ }^{11}$ Mouse IgG1 (clone C-04) monoclonal antibody (mAb), reactive with 
porcine cytokeratin peptide $18^{16}$ was used as primary antibody (Biovendor Laboratory Medicine, Heildelberg, Germany). Polyclonal $\mathrm{F}\left(\mathrm{ab}^{\prime}\right)_{2}$ rabbit anti mouse IgG:HRP antibody (AbD Serotec, Oxford, UK) was used as secondary antibody. For uncovering of tissue antigens fixed with formalin, we used a stabilized proteolytic enzyme mixture in an antigen retrieval kit (Abcam, Cambridge, UK), prior the application of primary antibody.

At age of 4 weeks, the pigs were randomly assigned into three groups comprising 5 animals each. After 2 days of accommodation, pigs were treated as follows: i) control pigs received $5 \mathrm{~mL}$ of saline intramuscularly (i.m.), at day 0 ; ii) pigs from the first group of principals were i.m. primed with levamisole (Nilverm ${ }^{\oplus}$; Pliva, Zagreb, Croatia) at the immunostimulatory dose of $2.5 \mathrm{mg} / \mathrm{kg}$ over three consecutive days $(-2,-1,0)$; and iii) the second group of principals were intragastrically (i.g.) immunized with $10^{10} \mathrm{CFU} / \mathrm{mL}$ of $\mathrm{F} \mathrm{ac}^{+}$non-ETEC vaccine candidate strain 2407 in $60 \mathrm{~mL}$ of Trypticase soya bujon (TSB), at day 0 . Seven days later all pigs were i.g. challenged with $10^{10} \mathrm{CFU} / \mathrm{mL}$ of F4ac $^{+}$ETEC strain 11-800/1/94 and two out of each group were euthanatized at day 13 and sampled for immunohistology.

Immediately following euthanasia, the samples of ileum were fixed in $10 \%$ neutralbuffered formalin ( $\mathrm{pH}$ 7.0-7.6) containing 4\% formaldehyde for 24 hours. Thereafter, the tissues specimens were dehydrated by graded alcohol solutions (in 75\%, 80\%, 95\%, 100\% ethanol), washed with xylene as a clearing agent and incubated in the paraplast embedding medium (Sigma, Deisenhofen, Germany). Following incubation, paraplastembedded specimens were cut into 5-6 $\mu \mathrm{m}$ thick serial sections and floated on a water bath containing distilled water heated to approximately $42^{\circ} \mathrm{C}$. The selected sections were picked up with the precoated slides and dried horizontally on a warming tray overnight at $37^{\circ} \mathrm{C}$. Paraplast-embedded ileal specimens were dewaxed in xylene, hydrated in graded alcohol solutions (in 100\%, 100\%, 95\%, 80\%, $75 \%$ ethanol) and immersed in distilled water. Endogenous peroxidase was blocked with $3 \%$ aqueous hydrogen peroxide solution for 30 minutes at room temperature, and nonspecific binding was blocked by $5 \%$ rabbit serum and $5 \%$ pig serum diluted in phosphate-buffered saline (PBS), for 30 minutes prior to staining. Then, the sections were incubated overnight at $4{ }^{\circ} \mathrm{C}$ with mouse mAb against cytokeratin peptide 18 (1:50 dilution). The secondary antibody $\mathrm{F}(\mathrm{ab})_{2}$ rabbit anti-mouse IgG HRP conjugate diluted 1:500 in PBS was incubated at room temperature for 1 hour. The reaction was visualized using a $0.05 \%$ solution of 3,3 diaminobenzidine tetrachloride (DAB) in 0.05 M Tris- $\mathrm{HCl}$ (pH 7.6) containing 0.01\% $\mathrm{H}_{2} \mathrm{O}_{2}$.
The slides were dehydrated by graded alcohol solutions and mounted in Canada balsam. The number of $\mathrm{M}$ cells in immunohistochemically stained tissue sections of ileum was determined by the computer-assisted quantitative analysis. A light microscope equipped with a video camera was interfaced with a desktop computer containing live video/computer graphics adapter and commercial imaging Lucia G software.

Statistical validation was performed on 12 randomly selected digital image fields of the average area of $700,480 \mu^{2}$ per 5 tissue sections of 2 pigs from each of three experimental groups. The antecedent testing showed that, analizying more than 10 fields in each of 5 tissue samples from one pig per group, there were no significant deviations in the cell counts of individual pig. Levels of significance of differences between principal and control pigs were determined by two-tailed Student's $t$ test. The results deviating from the null hypothesis at a level of $\mathrm{P}<0.01$ were considered as significant.

\section{Results and Discussion}

Figures 1, 2 and 3 show the immunohistochemical identification of cytokeratin peptide $18^{+} \mathrm{M}$ cells within the villous epithelium of the ileum of weaned pigs. It is visible that these cells were quite scarce in the ileum of control/nonpretreated and challenged pig (Figure 1). Conversely, numerous $M$ cells were found within the villous epithelium of ileum of levamisole-primed and challenged pig (Figure 2). As in the control/nonpretreated and challenged pigs, the M cells were rarely and diffusely scattered as well in the villous epithelium of ileum of vaccinated and challenged pigs (Figure 3 ). Generally, the $\mathrm{M}$ cells are rather solitary interspersed between enterocytes than as in small clusters (Figures 1, 2 and 3), and none were found to be located within the FAE regions of the ileum of 6 -weeks-old pigs. The question of how does and where these cells are distributed in the immunologically mature pigs (older than 7-9 weeks) remains still unanswered.

Numerical data on ileal M cells of pigs from three experimental groups as determined by computer-assisted morphometric analyses are shown in Table 1. In addition, the proportions of $M$ cells were expressed as a ratio between number of $M$ cells in the principal groups (no. increased or decreased) and that in the control group (where no. of the cells $=100 \%$ or 1.00 ). The quantitative phenotypic analyses showed that levamisole-primed and challenged pigs had significantly increased numbers $(\mathrm{P}<0.01)$ of ileal M cells, compared with the values obtained in the control nonprimed and chal-

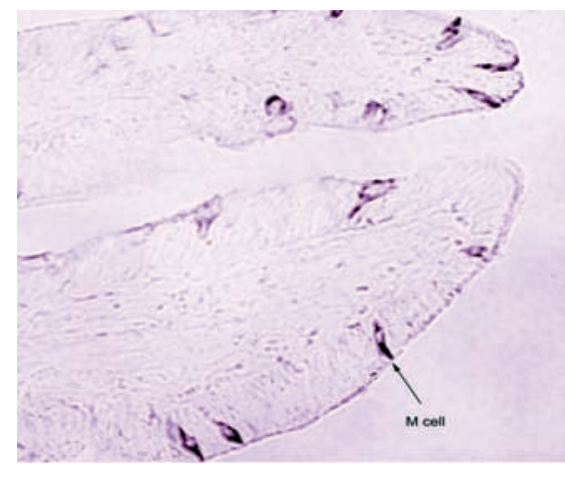

Figure 1. Immunohistochemical finding of cytokeratin peptide $18^{+} \mathrm{M}$ cells in ileal villous epithelium of control (at day $0, i . m$. received saline as a placebo) and challenged (at day 7 , perorally received pathogenic F4ac ${ }^{+}$ETEC strain) pig aging 6 weeks; original magnification $400 x$.

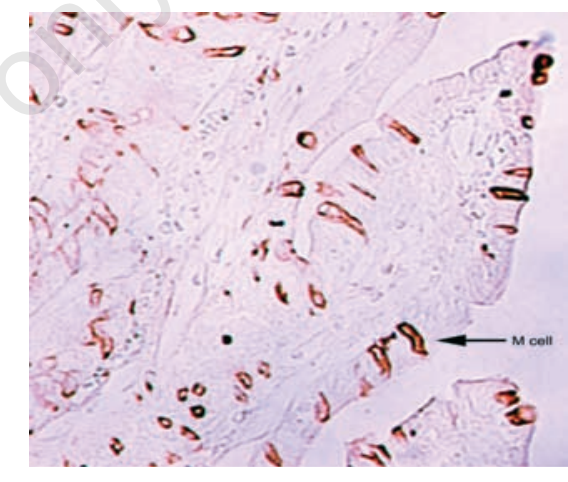

Figure 2. Immunohistochemical finding of cytokeratin peptide $18^{+} \mathrm{M}$ cells in ileal villous epitheliumof levamisole-primed (at days $-2,-1$ and 0 , i.m. received the drug) and challenged (at day 7 , perorally received pathogenic F4ac ${ }^{+}$ETEC strain) pig aging 6 weeks; original magnification $400 x$.

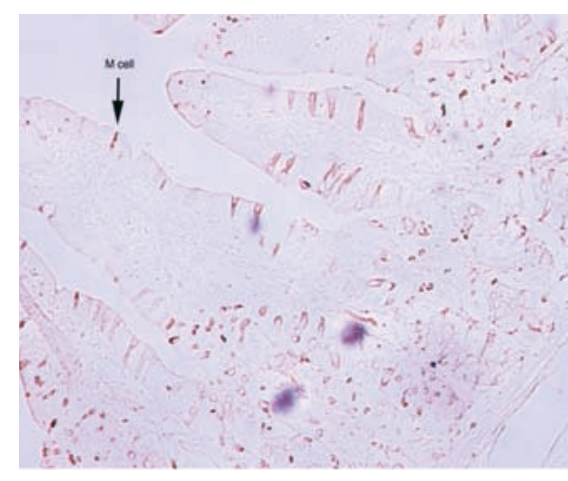

Figure 3. Immunohistochemical finding of cytokeratin peptide $18^{+} \mathrm{M}$ cells in ileal villous epithelium of experimentally vaccinated (at day 0 , perorally received vaccine candidate F4ac $^{+}$non-ETEC strain) and challenged (at day 7 , perorally received pathogenic F4ac ${ }^{+}$ETEC strain) pig aging 6 weeks; original magnification $400 x$. 
lenged pigs. The proportion of these cells in levamisole-pretreated pigs was $76 \%$ higher. In the vaccinated and challenged pigs only slightly increased (by 6\%) proportion of M cells was recorded. However, this increase was not significantly different from the numerical values obtained for control pigs.

Recently, we have reported, based on the histomorphometric quantification of porcine intestinal immune cells, that it is possible to differentiate the responses of pigs immunized with levamisole-adjuvanted experimental mucosal vaccines against PWC from those of nonimmunized pigs..$^{10,11}$ Based upon these observations, we highlighted the query of whether and how the already recognized immunogenicity/adjuvanticity of levamisole ${ }^{8,9}$ can influence de novo differentiation of the antigen-sampling $\mathrm{M}$ cells and consequently provide more feasible and effective immunization with mucosally delivered vaccines against enteric pathogens, such as porcine ETEC. In the case of positive answer, the study on development of an effective $\mathrm{M}$ cell-targeted vaccine against porcine PWC should be adjuvanted with levamisole in order to circumvent weak or tolerogenic responses. The successful protection of pigs vaccinated against PWC established by levamisole-adjuvanted live avirulent $E$. coli vaccine was previously reported. ${ }^{17}$ Moreover, these authors showed that pretreatment of weaned pigs with levamisole synergizes the effectiveness of a live oral $\mathrm{F}_{4} \mathrm{ac}^{+}$nonETEC vaccine by stimulating $\mathrm{T}$ cell responses in the ileal Peyer's patches. ${ }^{8}$ More recent research has shown that levamisole may also elicit intestinal humoral immune response of weaned pigs to vaccine candidate $\mathrm{F} \mathrm{ac}^{+}$nonETEC strain by stimulating proliferation of intestinal IgA ${ }^{+}$plasma cells. ${ }^{9}$

The present study confirmed cytokeratin 18 peptide as a specific marker for porcine $\mathrm{M}$ cells, which enabled their identification, localization and morphometric quantification in the ileal mucosa of weaned pigs. The cytokeratin $18^{+}$cells were found only within villous epithelial layer, regardless the treatments applied. Up to our knowledge, this is the first report on such location of $M$ cells in swine. This finding is in agreement with the recent identification and characterization of the intestinal villous $M$ cells in rodents and humans. ${ }^{18}$ These authors postulated that villous $\mathrm{M}$ cells might develop from the immature enterocytes upon exposure to foreign antigens or pathogens. Since the pigs in our experiment were conventionally reared, and additionally exposed to the antigens of non-ETEC/ETEC strains, it is very unlikely that they had none of traditional FAE-associated M cells. However, we did not observe $M$ cells within the FAE region of the ileum. Ileal villous $\mathrm{M}$ cells were significantly numerous $(\mathrm{P}<0.01)$ in levamisole

Table 1. Morphometric values of cytokeratin peptide $18^{+} \mathrm{M}$ cells in villous epithelium of the ileum from pigs immunized either with levamisole (day $-2,-1$ and 0 ) or with vaccine candidate F4ac ${ }^{+}$non-ETEC strain (day 0) and challenged with F4ac ${ }^{+}$ETEC strain (day $7)$; the results are expressed as mean values and standard deviations $(\mathrm{M} \pm \mathrm{SD})$ of number of the cells per $\mu^{2}$ of tissue section field.

\begin{tabular}{|c|c|c|c|}
\hline Treatment $^{\mathrm{a}}$ & $\begin{array}{l}\text { M.SD number of ileal M } \\
\text { cells in } 6 \text {-weeks-old pigs }\end{array}$ & Index ${ }^{e}$ & $\begin{array}{l}\text { Increase/ } \\
\text { decrease }\end{array}$ \\
\hline None $^{d}+$ F4 $\mathrm{ac}^{+}$ETEC & $6.12 \times 10^{-5} \pm 9.44 \times 10^{-6}$ & 1.00 & / \\
\hline Levamisole + F4ac ${ }^{+}$ETEC & $1.08 \times 10^{-4} \pm 1.25 \times 10^{-5 *}$ & 1.76 & +0.76 \\
\hline $\mathrm{F} 4 \mathrm{ac}^{+}$non-ETEC $+\mathrm{F} \mathrm{ac}^{+}$ETEC & $6.47 \times 10^{-5} \pm 1.95 \times 10^{-6}$ & 1.06 & +0.06 \\
\hline
\end{tabular}

${ }^{\mathrm{a}}$ Groups comprised five 4-weeks-old pigs each. ${ }^{\mathrm{b}} \mathrm{As}$ counted in 12 randomly selected fields of the average area of $700,480 \mu \mathrm{m}^{2}$ per sample from 2 pigs (euthanatized at day 13) per group. 'Ratio between number of $\mathrm{M}$ cells in the principal groups and that (no. of the cells $=100 \%$ or 1.00$)$ in the control group. ${ }^{\mathrm{d} C o n t r o l}$ pigs received saline at day 0 as a placebo. ${ }^{*}$ Significantly higher $(\mathrm{P}<0.01)$ than in the control pigs.

pretreated/challenged pigs, and only slightly, but not significantly numerous, in vaccinated/ challenged pigs compared with nonpretreated/challenged control pigs. The latter observation could be explained by our previous experiment, where vaccine candidate $\mathrm{F}_{18 \mathrm{ac}^{+} \text {non- }}$ ETEC strain was passing through the intestines almost three times faster than $\mathrm{F} \mathrm{ac}^{+}$ ETEC challenge strain. ${ }^{10}$ Unlike F4ac ${ }^{+}$ETEC challenge strain used in the latter and current study, it seems that both vaccine candidate strains (F4ac ${ }^{+}$and $\mathrm{F} 18 \mathrm{ac}^{+}$non-ETEC) exhibited weaker affinity for adhesion to the enterocyte receptors. Such adhesion is a prerequisite for stimulation of the intestinal mucosal immunity preceded by development of M cells from enterocytes upon exposure to enteric pathogens, i.e. F4ac ${ }^{+}$ETEC.

The origin and differentiation mechanism of $\mathrm{M}$ cells are still matter of controversy. It has been postulated that $\mathrm{M}$ cells represent a separate cell lineage that does not derive from enterocytes in the dome regions. ${ }^{19}$ These authors imply that bacteria-induced up-regulation of particle transport into Peyer's patch domes can be ascribed to an increased transportation rate of $\mathrm{M}$ cells, but not to an increased de novo formation of $\mathrm{M}$ cells. On the other hand, several authors suggested that transport of intraluminal antigens can be upregulated by de novo formation of $\mathrm{M}$ cells from enterocytes. ${ }^{20,21}$ Recently, it has been identified a possible intermediate $\mathrm{M}$ cell/enterocyte cell type in upper regions of the dome in pigs. ${ }^{22}$ Since it is recognized that lymphoepithelial interactions and soluble factors provide important signals for differentiation of $\mathrm{M}$ cells ${ }^{23}$ it would be reasonable to assume that levamisole might indirectly influence de novo formation of porcine intestinal villous $M$ cell phenotype by stimulating differentiation and proliferation of lymphocyte subsets in the lamina propria and Peyer's patches of weaned pigs, as we reported earlier. ${ }^{8,10,11,17,24}$

The current study has implied that levamisole may also affect differentiation and proliferation of porcine $\mathrm{M}$ cells by increasing their numbers in the intestinal villous epithelium. Historically, nearly all attention was focused on M cells within the FAE and their interactions with the underlying immune cells residing Peyer's patches, the major inductive sites in the intestine. However, current evidence indicates that the intestinal villous $M$ cells are functionally analogous to the FAE residing $M$ cells and that they may compensate for their functions, independently of Peyer's patches. Thus, it would be tempting to suggest that our observation of levamisole-stimulated proliferation of the ileal villous $M$ cells may have some relevance to the process of delivery of new mucosal vaccines against porcine PWC to the immune cells populating intestinal lamina propria. However, the interactions between M cells lying on the intestinal villi and the immune cells distributed in the underlying lamina propria are still largely unknown and further studies are required.

\section{References}

1. Nagy B, Fekete PZ. Entererotoxigenic Escherichia coli in veterinary medicine. Int J Med Microbiol 2005;295:443-54.

2. Lalles JP, Bosi P, Smidt H, Stokes CR. Weaning- A challenge to gut physiology. Livestock Sci 2007;108:82-93.

3. Van den Broeck W, Cox W, Goddeeris B M. Receptor-dependent immune responses in pigs after oral immunization with $\mathrm{F} 4$ fimbriare. Infect Immun 1999;67:520-6.

4. Yamanaka T, Straumfors A, Morton H, Fausa 0, Brandtzaeg P, Farstad I. M cell pockets of human Peyer's patches are specialized extensions of germinal centers. Eur J Immunol 2001;31:107-17.

5. Cox E, Van der Stede Y, Verdonck F, Snoeck V, Van den Broeck W, Goddeeris B. Oral immunization of pigs with fimbrial antigens of enterotoxigenic E. coli: an interesting model to study mucosal immune 
mechanisms. Vet Immunol Immunopathol 2002;87:287-90.

6. Stokes CR, Bailey M, Haverson K, Harris C, Jones $\mathrm{P}$, Inman $\mathrm{C}$ et al. Postnatal development of intestinal immune system in piglets: implications for the process of weaning. Anim Res 2004;53:325-34.

7. Bailey M, Haverson K, Inman C, Harris C, Jones P, Corfield G et al. The development of the mucosal immune system pre- and post-weaning: balancing regulatory and effector functions. Proc Nutr Soc 2005; 64:451-7.

8. Božić F, Lacković $\mathrm{G}$, Kovšca Janjatović A, Smolec 0, Valpotić I. Levamisole synergizes experimental F4ac+ Escherichia coli oral vaccine in stimulating ileal Peyer's patch $\mathrm{T}$ cells in weaned pigs. J Vet Pharmacol Ther 2006;29:199-204.

9. Janjatović AK, Lacković G, Božić F, Popović M, Valpotić I. Levamisole synergizes proliferation of intestinal IgA+ cells in weaned pigs immunized with vaccine candidate F4ac+ non-enterotoxigenic Escherichia coli strain. J Vet Pharmacol Ther 2008;31:328-33.

10. Kovšca Janjatović A, Lacković G, Božić F, Spoljaric D, Popovic M, Valpotic $\mathrm{H}$ et al. Histomorphometric characteristics of immune cells in small intestine of pigs per orally immunized with vaccine candidate F18ac+ nonenterotoxigenic E. coli strain. Eur J Histochemistry 2009;53:189-98.
11. Kovšca Janjatović A, Lacković G, Božić F, Kezic D, Popovic M, Valpotić $\mathrm{H}$ et al. Histomorphometric evaluation of intestinal cellular immune responses in pigs immunized with live oral F4ac+ nonenterotoxigenic E. coli vaccine against postweaning colibacillosis. Eur J Histochemistry 2010;54:18-24.

12. Gebert A, Rothkötter HJ, Pabst R. M cells in Peyer's patches of the intestine. Int Rev Cytol 1996;167:91-159.

13. Torché AM, Jouan H, Le Corre P, Albina E, Primault R, Jestin A et al. Ex vivo and in situ PLGA microspheres uptake by pig ileal Peyer's patch segment. Int J Pharm 2000;201:15-27.

14. KouLee R, Chen WX. M cell-targeted delivery of vaccines and therapeutics. Exp Opin Drug Deliv 2008;5:693-702.

15. Miller H, Zhang J, KuoLee R, Patel GB, Chen W. Intestinal $\mathrm{M}$ cells: The fallible sentinels? World J Gastroenterol 2007;13: 1477-86.

16. Gebert A, Rothkötter HJ, Pabst R. Cytokeratin 18 is an M-cell marker in porcine Peyer's patches. Cell Tiss Res 1994;276:213-21.

17. Božić F, Bilić V, Valpotić I. Levamisole mucosal adjuvant activity for a live attenuated Escherichia coli oral vaccine in weaned pigs. J Vet Pharmacol Ther 2003; 26:225-31.

18. Jang MH, Kweon MN, Iwatani K,
Yamamoto M, Terahara K, Sasakawa C et al. Intestinal villous $M$ cells: an antigen entry site in the mucosal epithelium. Proc Natl Acad Sci USA 2004;101:6110-5.

19. Gebert A, Steinmetz I, Fassbender S, Wendlandt KH. Antigen transport into Peyer's patches: increased uptake by constant numbers of $\mathrm{M}$ cells. Am J Pathol 2004;164:65-72.

20. Savidge TC, Smith MW. Evidence that membranous (M) cell genesis is immuneregulated. Adv Exp Med Biol 1995;371A: $239-41$.

21. Sierro F, Pringault E, Assman PS et al. Transient expression of M-cell phenotype by enterocyte-like cells of the follicle-associated epithelium of mouse Peyer's patches. Gastroenterology 2000;119:734-43.

22. Miyazawa K, Aso H, Kanaya T, Kido T, Minashima T, Watanabe K et al. Apoptotic process of porcine intestinal M cells. Cell Tiss Res 2006;323:425-32.

23. Neutra MR, Mantis NJ, Kraehenbuhl JP. Collaboration of epithelial cells with organized mucosal lymphoid tissues. Nat Immunol 2001;2:1004-9.

24. Božić F, Lacković G, Prevendar Crnić A, Sakar D, Valpotić I. Levamisole stimulates intestinal T-cell-mediated immune responses of weaned pigs to vaccination against colibacillosis. J Vet Pharmacol Ther 2003a;26:82-307. 